\title{
Atendimento emergencial em laceração de pescoço grau III com comprometimento vascular: relato de caso
}

Priscila Aparecida dos Santos;, Fernanda Fonseca, Alfredo Saraceni Basilio, Leticia Ramalho Izzo, Gabriel Vinicius Rios Arantes, Wagner Aparecido de Oliveira Mota, Pedro Henrique Pinto, Verena Hildegard Gyárfas Wolf, Francisco Antônio de Toledo Mello Neto, Alex Eduardo Alves Martins

Fundação Municipal de Ensino Superior de Bragança Paulista (FESB), Bragança Paulista, SP, Brasil

*Autor correspondente

e-mail: priscila-ap-santos1@hotmail.com

\section{Resumo}

A cicatrização da pele é alvo de diversos estudos, principalmente na área clínica, científica e econômica, devido a grande ocorrência de feridas causadas por traumas na espécie equina. Os equinos apresentam atitudes de fuga, resultando em respostas rápidas a qualquer estímulo de perigo, levando a ações traumáticas externas, como lesões por arame farpado ou liso, podendo gerar grandes quadros de lacerações e hemorragias. Para tanto, é necessária a ação rápida para o controle desse sangramento, restabelecendo as funções cardiovasculares do paciente, principalmente em casos onde há comprometimento de vasos calibrosos e formação de feridas extensas. Normalmente, essas são tratadas por segunda intenção, pois apresentam características como bordos distantes e em aposição ou ainda se apresentam contaminadas por agentes infecciosos ou corpos estranhos, além de apresentar um custo benefício bastante satisfatórios. Existem diversos métodos terapêuticos utilizados para o tratamento dessas feridas, porém a maioria resulta em retardo da cicatrização e tecido de granulação exuberante. Um equino, macho, da raça Mangalarga Marchador, com 4 anos de idade, pesando $350 \mathrm{~kg}$, deu entrada no Hospital Veterinário Dr. Bernardo Aronovich- HVET FESB, no mês de janeiro de 2017, apresentando um quadro hemorrágico devido a uma lesão de descontinuidade na região peitoral de aproximadamente $50 \mathrm{~cm}$ de comprimento e $20 \mathrm{~cm}$ de diâmetro. Na anamnese, relatou-se que a lesão foi provocada por arame liso, sendo identificada aproximadamente 4 horas depois do ocorrido. Ao exame clínico, os parâmetros se apresentavam dentro da normalidade. Optou- se por sedação do paciente para a realização da hemostasia com compressas, ligadura de vasos acometidos e debridamento da ferida. Devido à localização da lesão, extensão e contaminação local não foi possível suturar os bordos da ferida, optando-se pelo fechamento por segunda intenção. Dentre a terapia instituída empregou-se o uso de ácido tranexânico $15 \mathrm{mg} / \mathrm{kg}$, sulfadoxina com trimetoprim $15 \mathrm{mg} /$ $\mathrm{kg}$, Flunixina meglumina $1.1 \mathrm{mg} / \mathrm{kg}$. Durante o período de internação foi realizada a limpeza do local com 
clorexidina 2\%, pomada Furanil ${ }^{\circledR}$ associada ao Unguento Chemitec ${ }^{\circledR}$, carvão ativado, açúcar, Barbatimão, soro autólogo e curativo local utilizando-se malha tubular e compressa. 0 animal retornou à propriedade três dias após o seu ingresso, continuando o tratamento tópico instituído até a completa cicatrização da ferida. Foi prescrito Sulfametoxazol e Trimetoprim $25 \mathrm{mg} / \mathrm{kg}$. Após três meses do início do tratamento, houve redução significativa dos bordos da ferida. Com isso, um bom atendimento emergencial, incluindo a contenção de danos imediatos e tratamento adequado de uma ferida extensa, auxilia e favorece que o prognóstico do paciente seja favorável.

Palavras-chave: Laceração. Hemorragia. Arame liso. 